\title{
The Analysis on Financial Cooperative Controlling Mechanism of Enterprise Group
}

\section{Ziqin Feng}

School of Management and Economics, North China University of Water Resources and Electric Power, Zhengzhou, China. E-mail: fzq_2004_fzq@sina.com

Received July $18^{\text {th }}, 2010$; revised September $24^{\text {th }}, 2010$; accepted October $25^{\text {th }}, 2010$.

\begin{abstract}
As the core of modern market economy, enterprise group is an advanced form of organization after productive forces reached to a certain stage. For the reason of complexity and specificity of organizational form of enterprise group, the issue of financial cooperative control has been widespread concerned by theorists. Although many researches have been done, but there are still lacking of systematic research results especially in the fields of mechanism of financial cooperative control. After exploring the relationship of value effect and financial control, this paper puts forword a system model of financial cooperative control. It also gives a system analysis including system hierarchy analysis, synergy analysis and coupling analysis. All of these can provide a decision making support for the collaborative management of enterprise group.
\end{abstract}

Keywords: Enterprise Group, Financial Cooperative Control, Mechansim, Value Effect

\section{Introduction}

With the rapid progress of modern science and management techniques, the management of enterprise group $[1,2]$ is facing with multiple challenges including internal control to inter-organizational collaboration, single communication to multi-dimensional information transfer and fixed value process to flexible value process conversion, which make internal-external collaboration [3] of enterprise group and coordination of industrial chain becoming increasingly important. "Dynamic team, management coordination" is becoming the macro trends of organizational change of enterprise group. As a complex economic system, enterprise group has a value chain framework which includes multi strategic entities, various investing resources and multiple interest relationship. However, it is the basic requirement for enterprise group to ensure a long-term effective value-chain operation by financial cooperative control aiming as management coordination and value effect [4].

To begin with, management coordination is a fundamental means for enterprise group to play its overall advantages, the essential requirement of which is to achieve complementary advantages and function multiply to ensure the generation of value effect under the joint action of various elements [5]. Management coordination is a system management method which can make the system achieve self-organization from one order state to another. Firstly, it is a management method under the guidance of synergy which can promote the interaction of subsystems or elements when the system is in the critical or changing state. Secondly, it can make the system achieve coherence and complementarity by using of various management methods according to synergy rules [6]. Management coordination emphasizes collaboration and coordination of system elements. It is not only the value effect achievement of self-organization of enterprise group but also the specific application of "Dynamic Synergy View" and "Coupling Synergy View". Therefore, the realization of value effect of enterprise group must on the basis of management coordination.

Secondly, featuring dynamic and coupling, financial cooperative control is the concrete application of synergy theory and control theory in financial management of enterprise group, the aims of which are cooperative controlling of financial strategy, optimizing and allocation of financial resources and coordination and integration of financial relations to promote the value creation abilities of enterprise group. Enterprise group is a multi-dimensional value creation system which needs continuous value inflow and outflow, but the formation and lasting of value stream is ensured by financial activities. So, enterprise group can 
reduce operating costs and achieve operating income to ensure the effective cycle of value stream. However, the multi-relationship of financial makes it difficulty of financial management. Although the traditional financial management is simple and effective, but there are inefficient, ineffective and other defects to be improved and optimized. Financial cooperative control is the application of management coordination by absorbing modern collaborative concepts and controlling technologies. Enterprise group can provide a strong impetus to the lasting value cycle through financial cooperative control.

The rapid development of modern science and technology provides a technology support [7] for financial cooperative control of enterprise group to realize its value effect, and it can have a far-reaching impact on operational performance of enterprise group inevitably. To explore the mechanism of financial cooperative control is the important content of forming a system ideas and resolving the problem of financial cooperative control of enterprise group. From the existing literature, we can find that the research perspectives of enterprise group are mainly focused on connotations [8] and causes [9] of enterprise group, group governance [10], financial control [11] and management synergy effect etc., but not yet in the point of view of financial cooperative control. Although these researches have been supported by many relevant evidences which can provide theoretical guidance for strategic management of enterprise group, but it is the basic requirement of multidimensional and complex characteristics forming in the process of cooperative and competitive evolution to study the problem of enterprise group from dynamic and multi-dimensional perspective combining with modern theory and techniques. Needless to say, the existing researches have not comprehensively grasp the characteristics of nonlinear, dynamic and unpredictable of enterprise group, therefore the current governance system and synergy relationship have more flaws in promoting the financial operation of enterprise group. To study the mechanism of financial cooperative control of enterprise group is the prerequisite and basis for the overall effectiveness taking full play which is the main purpose of this paper. Firstly, this paper gives analysis model of financial cooperative control. Then, it analyzes the hierarchy, synergy and coupling of system. All of these can provide a decision making support for the collaborative management of enterprise group.

\section{Analysis Model}

\subsection{Relationship between Value Effect and Financial Control}

As a basic management method, financial cooperative control is closely related with the value effect of financial cooperative management what is a scarce resource concerned by stakeholders. Not only does it has the task to improve the execution of financial strategies, financial resource allocation and financial synergy relationship, but also it has the task to decreases transaction costs and improve the overall value creation ability. A well-functioning financial cooperative controlling system can has a vital role to value creation [12] of enterprise group. The operational efficiency of which can eventually reflect in the overall value effect of enterprise group by influencing financial management efficiency.

The relationship between financial control and value effect is $\cap$-shaped curve, which can be explained to marginal value effect diminishing law, that is to say the value effect level can increase along with the increasing of financial controlling power when it is not reached a certain degree, while the value effect level can decrease along with the increasing of financial controlling power after the value effect reaching maximum. Assuming $y=f(x)$ is a function expressing the relationship between value effect level and financial controlling power, which is a continuously differentiable strictly convex function. Then there are first derivative $d f / d x$ and second derivative $d^{2} f / d x^{2}$, and $d^{2} f / d x^{2}<0$. This paper adopts modified normal distribution density function to describe the relationship between value effect and financial controlling power. The relationship between value effect and financial control can be seen in Figure 1, and the mathematical expression can be expressed as:

$$
y=\alpha \cdot e^{\frac{-(x-\mu)^{2}}{\sigma^{2}}} 0<x<+\infty
$$

where $\mu>\sigma>0, \alpha>0 . \alpha$ is value effect coefficient which can determine value effect level. $\mu$ is a undetermined coefficient which can determine the location of value effect function. $\sigma$ representatives the ability of value effect which determine the shape of value effect function. There are different $\alpha, \mu$ and $\sigma$ to different enterprise group. According to the nature of function, $y=f(x)$ reaches to maximum when $x=\mu$ and there are inflection points when $x=\mu \pm \sigma$. In order to further analysis and research, this paper divides the relational area into five regions what are low financial controlling region, weak financial controlling region, financial cooperative controlling region, high financial controlling region and strong financial controlling region (see Figure 1 and Table 1). Then, we know that the value effect level is the best when $x=\mu$ and $y^{*}=\alpha$. And $y=\alpha e^{-0.25}$ when $x=\mu \pm 0.5 \sigma, y=\alpha e^{-1}$ when $x=\mu \pm \sigma$. Therefore, the scope of value effect level can be $\left[\alpha e^{-0.25}, \alpha\right]$.

Through the above analysis, we know that: 
- The relationship between value effect and financial control is $\cap$-shaped curve. When financial controlling power is less than $\mu$, the function is shown as monotonically increasing status $\left(f^{\prime}(x)>0\right)$ and the value effect will be increasing along with the financial controlling power. When the financial controlling power is equal to $\mu$, the value effect reaches to maximum. And when financial controlling power is greater than $\mu$, the function is shown as monotonically decreasing status $\left(f^{\prime}(x)>0\right)$ and the value effect will be decreasing along with the increasing of financial controlling power.

- Excessive financial control and inadequate financial control are not conducive to the generation of value effect, and financial cooperative control is a better area for enterprise group taking full play its value creation ability. The main reasons can be explained that excessive financial control will weaken activity of economic entities which can result in lower efficiency or higher costs and that inadequate financial control can constrain value effect by its over-relaxation to the activity of economic entities.

\subsection{System Model of Financial Cooperative Control}

The achievement of value effect of enterprise group must under the activity of financial cooperative control which is determined by the non-linear organizational character-

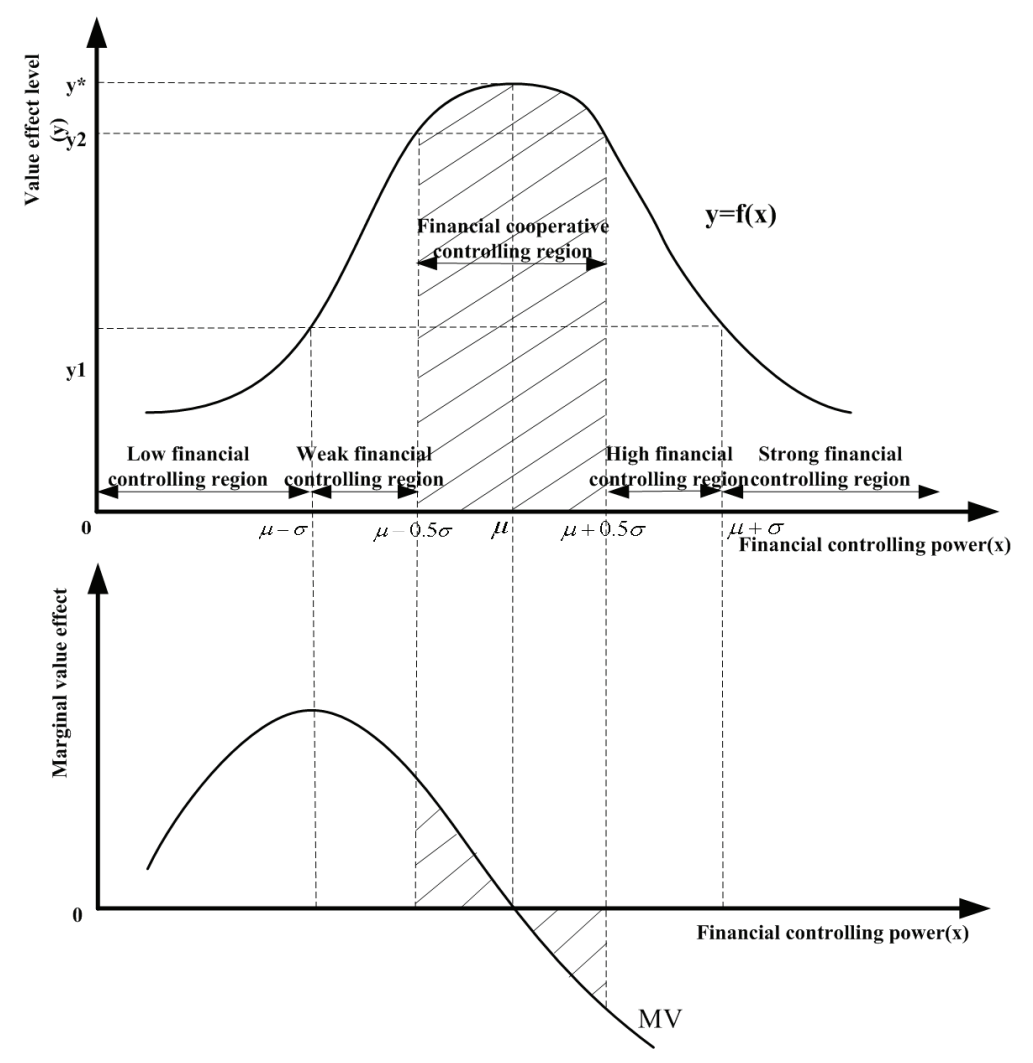

Figure 1. Relationship between value effect and financial control.

Table 1. Relatioship between financial controlling power and value effect.

\begin{tabular}{cccc}
\hline$x$ & $y$ & Type & Result \\
\hline$[0, \mu-\sigma)$ & {$\left[\alpha e^{-\frac{\mu^{2}}{\sigma^{2}}}, \alpha e^{-1}\right)$} & Low financial control & Inadequate control \\
{$[\mu-\sigma, \mu)$} & {$\left[\alpha e^{-1}, \alpha e^{-0.25}\right)$} & Weak financial control & Inadequate control \\
{$[\mu-0.5 \sigma, \mu+0.5 \sigma)$} & {$\left[\alpha e^{-0.25}, \alpha\right]$} & Financial cooperative control & Moderate control \\
{$[\mu, \mu+\sigma)$} & {$\left[\alpha e^{-1}, \alpha e^{-0.25}\right)$} & High financial control & Excessive control \\
{$[\mu+\sigma, \infty)$} & $\left(0, \alpha e^{-1}\right]$ & Strong financial control & Excessive control \\
\hline
\end{tabular}


istics such as dissipative structure, cooperative competition and dynamic coupling. Financial cooperative control is the basic need of long-term value creation which can be expressed as environment-adaptation value, synergyeconomic value and synergy-relation value. Analyzing from the value orientation of financial cooperative control, the motivation of environment-adaptation value determines the overall competitive advantage, the motivation of synergy-economic value determines the economic value and the motivation of synergy-relation value determines the win-win value. Analyzing from the influencing style of financial cooperative control, the motivetion of environment-adaptation value can affect the risk control capability and competitiveness, the motivetion of synergy-economic value can affect the degree of economic realization and the motivation of synergy-relation value can affect the input of specific assets of stakeholders. Analyzing from the relationship, the motivation of environment-adaptation value is an important force which can maintain the acquirement of synergyeconomic value and synergy-relation value, the motivetion of synergy-economic value is the premise and foundation of environment-adaptation value and synergyrelation value, the motivation of synergy-relation value is the ultimate goal of environment-adaptation value and synergy-economic value.

Environment-adaptation value, synergy-economic value and synergy-relation value are the important driving forces of financial cooperative control. When they are interaction at the balance power, the ability of financial cooperative control of enterprise group can be strengthen. However, when one of them is in the absolutely dominant position while the other are very weak, the result of financial cooperative control is possible to deviate from direction. For example, when environment-adaptation value is in the absolutely dominant position, the value aim of financial cooperative control may be committed to improving the system robustness to give up the synergy-economic opportunity and synergy-relation opportunity. Therefore, the generation of value effect of financial cooperative control of enterprise group needs the common driving force of the three values. And when the three values are in the state of mutually reinforcing, a greater value effect can be generated through financial cooperative control.

Environment-adaptation value, synergy-economic value and synergy-relation value can be expressed as three abilities what are financial-strategy cooperative control, financial-resource cooperative control and financial-relation cooperative control. The three abilities of financial cooperative control constitute the basic space system (see Figure 2). The system model of financial cooperative control includes three dimensions (X: Financial-strategy Cooperative Control, Y: Financial-resource Cooperative Control, Z: Financial-relation Cooperative Control). Assume the ability index of financial cooperative control is $\mathrm{Fc}$, and the ability indexs of financialstrategy cooperative control, financial-resource cooperative control and financial-relation cooperative control are $a, b, c$ respectively. Then the mathematical model of financial cooperative controlling ability can be expressed as:

$$
F_{C}=a \cdot b \cdot c
$$

\section{System Analysis}

\subsection{System Hierarchy of Financial Cooperative Control}

Synergy Theory thinks that every subsystems of any system have self-organizing process [13] to maintain their interaction and generate new stable ordered structure. Featuring nonlinear, dynamic and valuable [14], the financial cooperative controlling system of enterprise group is a complex system constituted by a number of subsystems. Analyzing from Synergetics, this system can be divided into three subsystems what are Financial-strategy Cooperative Controlling subsystem, Financial-resource Cooperative Controlling subsystem and Financial-relation Cooperative Controlling subsystem. These three subsystems are not isolated but a complete organism, their synergistic interactions promote the value effect of enterprise group. Analyzing from system hierarchy of financial cooperative control, Financial-strategy Cooperative Controlling subsystem is in the top level of system who stipulates the Organization Mission (OM) and Development Goals (DG). It is the direction layer of financial cooperative control which can coordinate resources and relationships of member com-

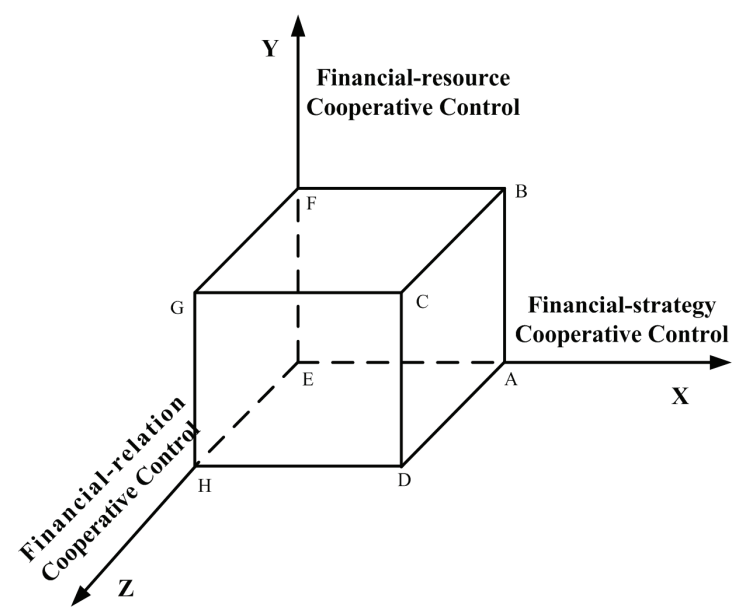

Figure 2. System model of financial cooperative control. 
panies to achieve a virtuous circle. Financial-resource cooperative controlling subsystem is in the middle of system that is the power endurances to promote the optimal of resources allocation. It is the ability layer of financial cooperative control which can promote the value creation ability. Financial-relation cooperative controlling subsystem is in the bottom of system who is the promise of conflict resolution of and reduce friction to play multi-activities. It is the supporting layer of financial cooperative control which can maintain group relationship (See Figure 3). Many indices can represent direction layer, ability layer and supporting layer (See Table 2).

\subsection{Synergy Analysis of Financial Cooperative Controlling System}

Enterprise group who has a multi-layer structure is a commonwealth of multiple companies linked by the ties

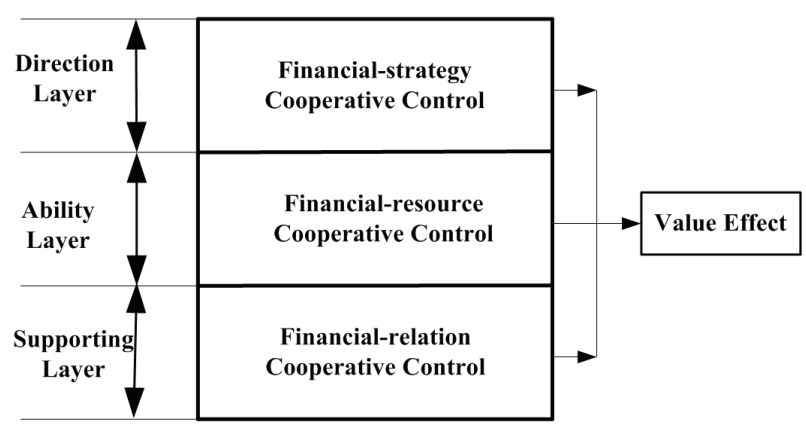

Figure 3. System hierarchy of financial cooperative control.

Table 2. Indices of financial cooperative controlling system.

\begin{tabular}{|c|c|c|}
\hline Dimension & Indice & Hierarchy \\
\hline \multirow{4}{*}{$\begin{array}{l}\text { Financial-strategy } \\
\text { Cooperative Control }\end{array}$} & $\begin{array}{l}\text { Market environment } \\
\text { adaptation degree }\end{array}$ & \multirow{4}{*}{$\begin{array}{l}\text { Direction } \\
\text { Layer }\end{array}$} \\
\hline & $\begin{array}{l}\text { Investment environment } \\
\text { adaptation degree }\end{array}$ & \\
\hline & $\begin{array}{l}\text { Financing environment } \\
\text { adaptation degree }\end{array}$ & \\
\hline & $\begin{array}{l}\text { Value creation rate of } \\
\text { investment capital }\end{array}$ & \\
\hline \multirow{3}{*}{$\begin{array}{l}\text { Financial-resource } \\
\text { Cooperative Control }\end{array}$} & Cash cycle turnover rate & \multirow{3}{*}{$\begin{array}{l}\text { Ability } \\
\text { Layer }\end{array}$} \\
\hline & Cash deferred payment rate & \\
\hline & $\begin{array}{c}\text { Free cash flow rate of } \\
\text { investment capital }\end{array}$ & \\
\hline \multirow{4}{*}{$\begin{array}{l}\text { Financial-relation } \\
\text { Cooperative Control }\end{array}$} & $\begin{array}{l}\text { Customer synergy } \\
\text { satisfaction degree }\end{array}$ & \multirow{4}{*}{$\begin{array}{l}\text { Supporting } \\
\text { Layer }\end{array}$} \\
\hline & $\begin{array}{l}\text { Employee synergy } \\
\text { satisfaction degree }\end{array}$ & \\
\hline & $\begin{array}{l}\text { Supplier synergy } \\
\text { satisfaction degree }\end{array}$ & \\
\hline & $\begin{array}{l}\text { Cash value added rate of } \\
\text { capital investment }\end{array}$ & \\
\hline
\end{tabular}

of assets and contract. The complex organizational relationship of enterprise group requires that the group and the member companies must maintain a collaborative and consistent strategy development so as to improve the overall strategy execution. In the fierce changing competitive environment, the aim of Financial-strategy cooperative control of enterprise group is to full play technical advantage, cost advantage, financial advantage and value creation advantage of member companies to ensure the input of continues cash flow and value flow in order to acquire a long-term and sustainable competitive advantage. Firstly, synergy strategy is the key and basis to realize financial strategy coordination. Ansoff pointed out that synergy strategy is a strategy which can make the overall value greater than the sum of each part of the value by successfully developing new business on how to identify the matching relation between their capabilities and opportunities [15]. Barzel thinks that synergy strategy is the strategy of overall business performance of enterprise group what is relative to the performance of a simple summary of each independent components [16]. Kantor believes that synergy strategy is a corporate strategy the aim of which is to get synergy profit. Li [17] pointed out that synergy strategy includes four dimensions what are cooperation and competition, symbiosis and win-win, dynamic adaptation and system global. Secondly, perfect corporate governance structure is the organizational endurances to realize financial strategy synergy. For the reason of the multi-corporation legal person characteristics, corporate governance is the prerequisite of validity of financial power allocation what can play "Incentive compatible" effect. Meanwhile, Financial-strategy cooperative control must emphasize overall-adaptation, resource-complementary and benefit-sharing. Only on the basis of strategic flexibility can the members combine their own values with the longterm value of enterprise group to use of financial resources maximally.

Narrow financial resource is refers only to material resource of enterprise while generalized financial resource is all the resources of enterprise [18] including production resources, technical resources, organizational resources and information resources, etc. Endowment theory suggests that the country who has adequate capitals will has a comparative advantage in capital-intensive goods and the country who has abundant labor force will has a comparative advantage in labor-intensive goods. Economies of scale theory points out that enterprise's scale economy constrained not only by resource conditions but also by the management capacity, financial capacity and market capacity. Porter argued that advanced factors of production are the decisive force in enterprise resource allocation, low-level factors of production is a 
necessary condition. Therefore, resources are the basis for enterprise to survive and develop, financial-resource cooperative control is a source of value creation. Including productive resources cooperative control, technical resources cooperative control, organizational resources cooperative control and information resources cooperative control, financial-resource cooperative control is refers to the financial ability for enterprise group to acquire and use of resources to create value which can be expressed as sustainable financing capacity, sustainable operating capacity, sustainable profit ability and capital structure optimization. Productive resources cooperative control is refers to the matching and complementary of these resources using in production and that whether these resources can become an effective support to scale economy and scope economy of enterprise group. Technical resources cooperative control is refers to whether the value creation ability of intellectual capital can become a source of technological innovation and the product differentiation and cost saving degree causing by technological innovation. Organizational resources cooperative control is refers to the advanced management processes and methods what can bring high efficiency and effectiveness for organization operation. Information resources cooperative control is refers to the sharing degree of internal information resources which can be expressed as information fluency, information authenticity and communication effectiveness, etc.

Enterprise group is a multi-relation and multi-interest contract collection, the complex hierarchy of which constitutes its basic organizational framework. Stakeholder theory points out that the relationship between stakeholders and enterprise is interest community which can be expressed as two aspects [19]. Firstly, for the reason of the investment of specific assets, stakeholders must require a corresponding profit from residual income of enterprise. Secondly, for the reason of the risk of their specific assets, stakeholders must retain a necessary controlling right to enterprise. For enterprise group, how to coordinate the interest relation and power relation of stakeholders has become an important part of financial management. Therefore, power distribution and interest balance are the centre of financial-relation cooperative control. Financial-relation cooperative control is the relation value cooperative controlling ability which can balance the value inputs and the residual claimants of stakeholders in the process of interaction between stakeholders and enterprise group. For the internal stakeholders, reasonable financial power allocation, earnings distribution, mutually beneficial trust relationships and interest conflicts resolving mechanisms are the keys to realize financial-relation cooperative control. Financial power allocation is the core of financial governance, the aim of which is to improve and adjust the position of stakeholders in financial governance to promote value creation and value added by improving management efficiency. Earnings distribution is the need of meeting the pursuit of value added of various stakeholders, and reasonable distribution model is the premise of residual relationship control. Trust relationship is the basic condition to maintain the existence of enterprise group, the effectiveness of which lies in information complete degree and rapid information feedback mechanism. Interest conflict is the basic manifestation of financial-relation cooperative control, the key of which is to establish an effective conflict resolution strategies. As for external stakeholders, supply chain cooperative control, capital chain cooperative control and tax cooperative control has become the important part of financial-relation cooperative control.

\subsection{Coupling Analysis of Financial Cooperative Controlling System}

Financial cooperative control is a complex space system, the key subsystems of which has coupling relations. To begin with, when the three are coupling line and in the state of benign interaction, the system shows positive emerging, and the value effect of enterprise group will be enhanced [20]. Next, when the three are disordered and isolated, the system shows negative emerging, and the value effect of enterprise group will be weakened (See Figure 4).

Coupling degree is the mathematical description of multi-subsystem, the method of which is to evaluate the order degree and future development capacity of system by calculating and analyzing the coupling degree of system. In order to better describe the coupling relation of subsystems of enterprise group, this paper adopts effect function and coupling function to build synergies mathematical model. Assume variable $u_{i} \quad(i=1,2,3)$ is the order parameter of financial cooperative controlling

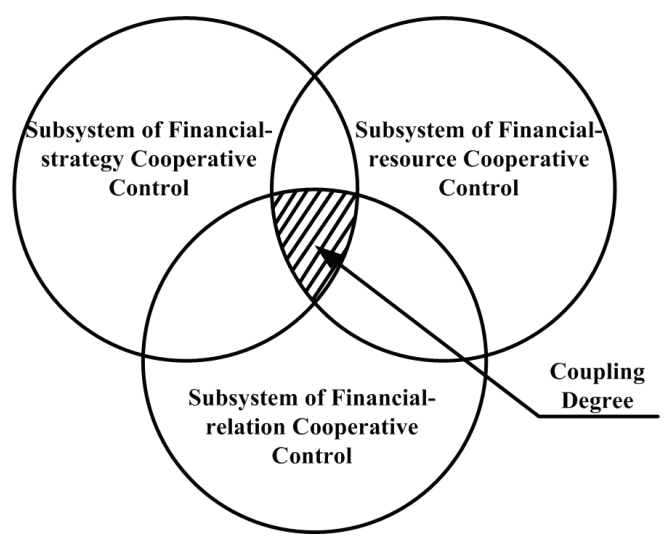

Figure 4. Coupling relation of financial cooperative control. 
system, $u_{i j}$ is the $j$-th index of $i$-th order parameter, the value of the index is $x_{i j}$, and $\max _{i j}$ is the maximum of the index, $\min _{i j}$ is the minimum of the index. If $u_{i j}$ is a positive function, the effect function of financial cooperative control of enterprise group can be expressed as:

$$
u_{i j}=\frac{x_{i j}-\min _{i j}}{\max _{i j}-\min _{i j}}
$$

If $u_{i j}$ is a negative function, the effect function of financial cooperative control of enterprise group can be expressed :

$$
u_{i j}=\frac{\max _{i j}-x_{i j}}{\max _{i j}-\min _{i j}}
$$

where $u_{i j} \in[0,1], u_{i j}$ is the contribution to system effect of variable $x_{i j}$ which reflects the satisfaction degree for every index to their targets.

If $u_{1}, u_{2}, u_{3}$ is the measure index of value effect of the three subsystems, then the coupling function can be expressed as:

$$
C_{3}=2\left(\frac{u_{1} \cdot u_{2} \cdot u_{3}}{\left(u_{1}+u_{2}\right) \cdot\left(u_{1}+u_{3}\right) \cdot\left(u_{3}+u_{2}\right)}\right)^{1 / 3}
$$

where $C_{3} \in[0,1]$. When $u_{1}=u_{2}=u_{3}, C_{3}=1$, the coupling degree of system is maximum, subsystems or elements within the system achieve positive resonance coupling, the system will tend to a new order structure (the system achieve positive emergence and the value effect is enhenced). When $C_{3}=0$, the coupling degree of system is minimum, subsystems or elements within the system is in the independent state, the system will tend to disorder (the system shows negative emergence and the value effect is weaken).

\section{Conclusions}

In this paper the author analyzes the mechanism of financial cooperative control of enterprise group. The main contributions of this paper can be summarized as follows:

1) It refers that management coordination is a fundamental means for enterprise group to play its overall advantages, the essential requirement of which is to achieve complementary advantages and function multiply to ensure the generation of value effect under the joint action of various elements.

2) It confirms that financial cooperative control is the concrete application of synergy theory and control theory in financial management of enterprise group, the aims of which are cooperative controlling of financial strategy, optimizing and allocation of financial resources and coordination and integration of financial relations to pro- mote the value creation abilities of enterprise group.

3) It puts forward a system model after exploring the relationship of value effect and financial control. The relationship between value effect and financial control can be explained to five regions: low financial controlling region, weak financial controlling region, financial cooperative controlling region, high financial controlling region and strong financial controlling region. The system model includes three dimensions what are financial-strategy cooperative controlling dimensions, financial-resource cooperative controlling dimension and financial-relation cooperative controlling dimension.

4) It gives a system analysis including system hierarchy analysis, synergy analysis and coupling analysis.

\section{REFERENCES}

[1] Hiroshi, "Interfirm Relations in an Enterprise Group: The Case of Mitsubishi," Japanese Economic Studios, Vol. 22, No. 10, 1982, pp. 53-82.

[2] R. Jankowski, "Preference Aggregation in Firms and Corporatist Organizations: The Enterprise Group as a Cellular Encompassing Organization," American Journal of Political Science, Vol. 33, No. 4, 1989, pp. 973-994.

[3] W. Bai, "Finance Management and Control of Enterprise Group," Chinese Development Press, Beijing, 2008.

[4] Y. Gong and Y. Liu, "Diversification Motivation and Its Value Effect," Statistical Research, Vol. 24, No. 10, 2007, pp. 94-96.

[5] D. Teece, G. Pisano and A. Shuen, "Dynamic Capabilities and Strategic Management," Strategic Management Journal, Vol. 18, No. 7, 1997, pp. 509-533.

[6] D. Xu and K. Li, "Management Coordination and Refinement," Science Press, Beijing, 2008.

[7] J. Bai, Y. Chen and Q. Li, "Innovative Collaboration and Its Influential Factors of Enterprise," Science Studies, Vol. 8, No. 4, 2008, pp. 410-413.

[8] Y. Chen, "Study on Financial Issues of Enterprise Group," Northeast University of Finance Press, Dalian, 2007.

[9] B. R. George, "The Organization of Industry," Economic Journal, Vol. 82, No. 327, 1972, pp. 883-896.

[10] S. Zhang, Z. Yu and Q. Liu, "Financial Controlling System of Enterprise Group," Financial and Economic Publishing House in China, Beijing, 2006.

[11] O. E. Williamson, "Corporate Financial and Corporate Governance," The Journal of Finance, Vol. 35, No. 10, 1998, pp. 567-589.

[12] H. Yang, "Value Effect of Corporate Control and Its Influence Factors," Tianjin University Press, Tianjin, 2006.

[13] Nicolis and Prigogine, "Self-organization in Nonequibibrium System from Dissipative Structures to Horder through Fluctuations," Wilety, NewYork, 1977.

[14] J. Hulland, "Use of Partial Least Squares (PLS) in Strate- 
gic Management Research: A Review of Current Studies," Strategic Management Journal, Vol. 20, No. 3, 1999, pp. 195-204.

[15] I. Ansoff, “Corporate Strategy,” McGraw-Hill, New York, 1965.

[16] R. Buzzell and B. Gale, "The PIMS Princilpes Linking Strategy to Performance," The Free Press, 1987.

[17] H. Li, "Study of Synergic Strategy Theory of Chinese Enterprise," Modern Economy, Vol. 22, No. 6, 2007, pp.
$71-74$.

[18] Z. Gou and H. Qi, "Study of Financial Strategy Management Object," Financial Research, Vol. 25, No. 7, 2002, pp. 52-54.

[19] R. Freeman, "Strategic Management: a Stakeholder Approach," Pitman, Boston, 1984.

[20] K. Ying and H. Xue, "Research on Synergy Effect of Enterprise Group's Management," East China Economic Management, Vol. 33, No. 10, 2004, pp. 135-138. 